\title{
The role of multilevel factors in geographic differences in bicycle crash risk: a prospective cohort study
}

\author{
Sandar Tin Tin", Alistair Woodward and Shanthi Ameratunga
}

\begin{abstract}
Background: Regular cycling plays an important role in increasing physical activity levels but raises safety concerns for many people. While cyclists bear a higher risk of injury than most other types of road users, the risk differs geographically. Auckland, New Zealand's largest urban region, has a higher injury risk than the rest of the country. This paper identified underlying factors at individual, neighbourhood and environmental levels and assessed their relative contribution to this risk differential.

Methods: The Taupo Bicycle Study involved 2590 adult cyclists recruited in 2006 and followed over a median period of 4.6 years through linkage to four national databases. The Auckland participants were compared with others in terms of baseline characteristics, crash outcomes and perceptions about environmental determinants of cycling. Cox regression modelling for repeated events was performed with multivariate adjustments.

Results: Of the 2554 participants whose addresses could be mapped, 919 (36\%) resided in Auckland. The Auckland participants were less likely to be Māori but more likely to be socioeconomically advantaged and reside in an urban area. They were less likely to cycle for commuting and off-road but more likely to cycle in the dark and in a bunch, use a road bike and use lights in the dark. They had a higher risk of on-road crashes (hazard ratio: 1.47; 95\% Cl: 1.22, 1.76), of which 53\% (95\% Cl: 20\%, 72\%) was explained by baseline differences, particularly related to cycling off-road, in the dark and in a bunch and residing in urban areas. They were more concerned about traffic volume, speed and drivers' behaviour.
\end{abstract}

Conclusions: The excess crash risk in Auckland was explained by cycling patterns, urban residence and factors associated with the region's car-dominated transport environment.

Keywords: Bicycling, Injury, Risk, Cohort studies, Mediation

\section{Background}

Using a bicycle, despite its proven health and other benefits [1-3], is rarely part of everyday travel in many countries due to concerns about traffic safety [4-7]. Cyclists generally bear a higher risk of injury than most other types of road users, per hour spent travelling [8,9] but the risk differs between and within countries [10-15]. This may be explained by geographic variations in population demographics, travel patterns, residential neighbourhoods and aspects of the physical environment. The 'safety in numbers' (or the 'risk in scarcity') effect is often cited as an

\footnotetext{
* Correspondence: s.tintin@auckland.ac.nz

Section of Epidemiology and Biostatistics, School of Population Health, University of Auckland, Private Bag 92019, Auckland 1142, New Zealand
}

explanation for a lower risk of injury in places with a higher level of cycling $[10,11,14]$ but the relative contributions of this and other factors are poorly understood.

As in many other countries, cycling is an under-used mode of transport in New Zealand [16,17]. Travel patterns vary across the sixteen census regions $[16,18]$ and so does the injury risk [14]. Auckland is the country's largest and fastest growing metropolitan region accommodating onethird of the total population [19] (a map of New Zealand is provided in Additional file 1). The region also has the lowest level of active travel [16]. Consistent with the national statistics $[14,20]$, our previous analysis of the data from the Taupo Bicycle Study shows that the risk of onroad bicycle crashes is higher in Auckland than the rest of

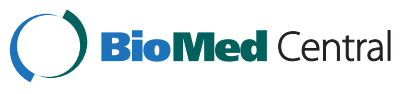

(c) 2013 Tin Tin et al.; licensee BioMed Central Ltd. This is an open access article distributed under the terms of the Creative Commons Attribution License (http://creativecommons.org/licenses/by/2.0), which permits unrestricted use, distribution, and reproduction in any medium, provided the original work is properly cited. 
the country [21]. This risk disparity may be mediated through multiple pathways involving differences in characteristics of the participating cyclists as well as broader contextual and environmental factors (Figure 1).

The Taupo Bicycle Study is a prospective cohort study designed to examine factors associated with regular cycling and injury risk. This paper used data from the study to assess the relative contribution of demographic, residential, cycling and behavioural risk factors in explaining the difference in crash risks between Auckland and the rest of the country, and to identify environmental factors that could play an important mediating role.

\section{Methods}

\section{Design, setting and participants}

The sampling frame comprised cyclists aged 16 years and over who enrolled online in the Lake Taupo Cycle Challenge, New Zealand's largest mass cycling event held each November. Participants have varying degrees of cycling experience ranging from competitive sports cyclists and experienced social riders to relative novices of all ages.

Recruitment was undertaken at the time of the 2006 event for the majority of participants, as described, in detail, elsewhere [22]. In brief, email invitations, containing a hyperlink to the study information page, were sent to 5653 contestants who provided their email addresses at registration for the event. Those who agreed to participate in the study were taken to the next page containing a web questionnaire and asked about demographic characteristics, general cycling activity and crash experience in the past twelve months and habitual risk behaviours with options ranging from 'never' to 'always'. The questionnaire was completed and submitted by 2438 cyclists ( $43.1 \%$ response rate). Another 190 cyclists were recruited from the 2008 event by including a short description about the study in the event newsletter. All participants were resurveyed in December 2009 using a web questionnaire containing similar questions as the baseline questionnaire. The participants were also asked to rate the importance of specified factors that would influence cycling for transportation. A total of 1537 participants completed the questionnaire with options ranging from 'not important at all' to 'very important'. Figure 2 presents the flow of study participation. Ethical approval was obtained from the University of Auckland Human Participants' Ethics Committee.

\section{Crash outcome data}

Crash outcome data were collected through record linkage to four administrative databases, covering the period from date of recruitment to 30 June 2011. All participants consented to link their data to the following databases.

In New Zealand, the Accident Compensation Corporation (ACC) provides personal injury cover for all residents and temporary visitors to New Zealand no matter who is at fault. The claims database is a major source of information on relatively minor injuries with over $80 \%$ of the claims relating to primary care (e.g., GPs, emergency room treatment) only [23]. Approval for record linkage was obtained from the ACC Research Ethics Committee.

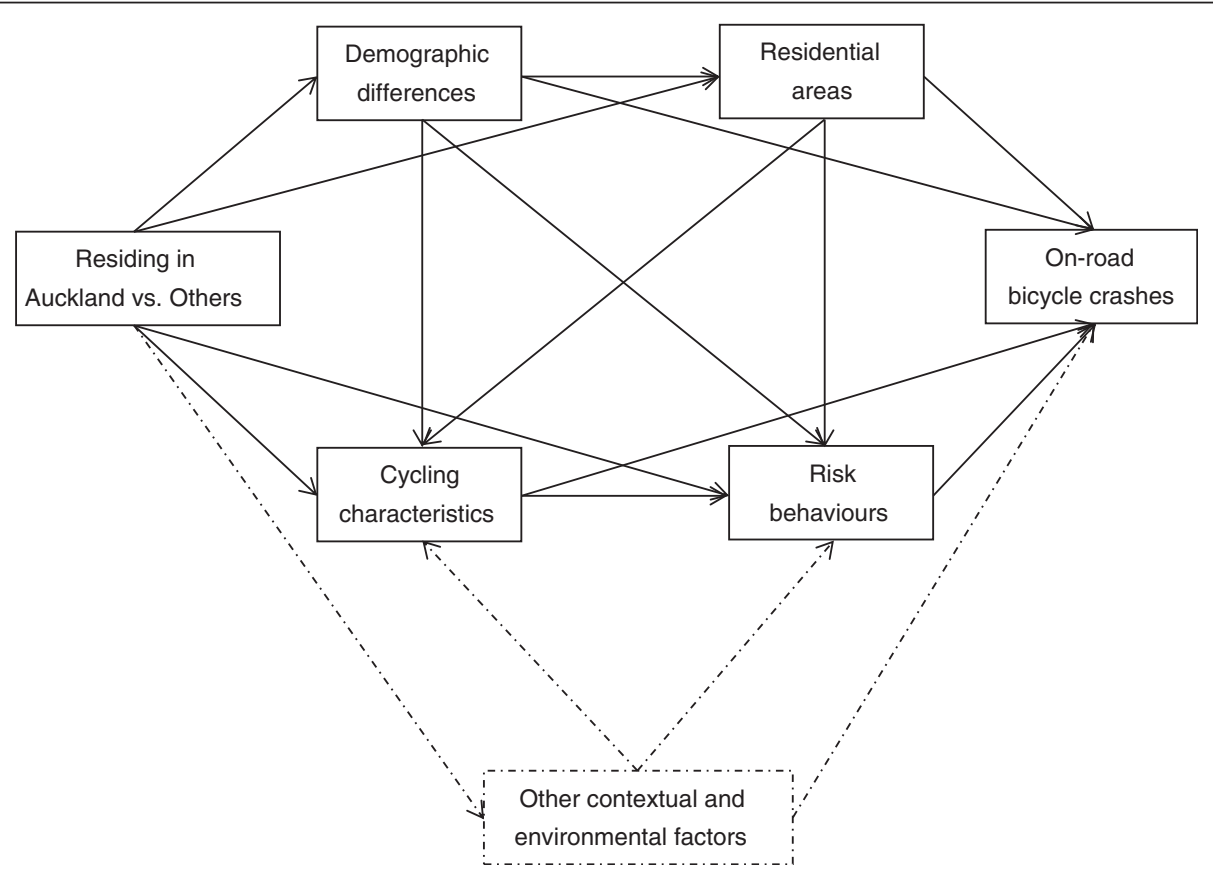

Figure $1 \mathrm{~A}$ simplified causal diagram depicting the role of mediating factors. 


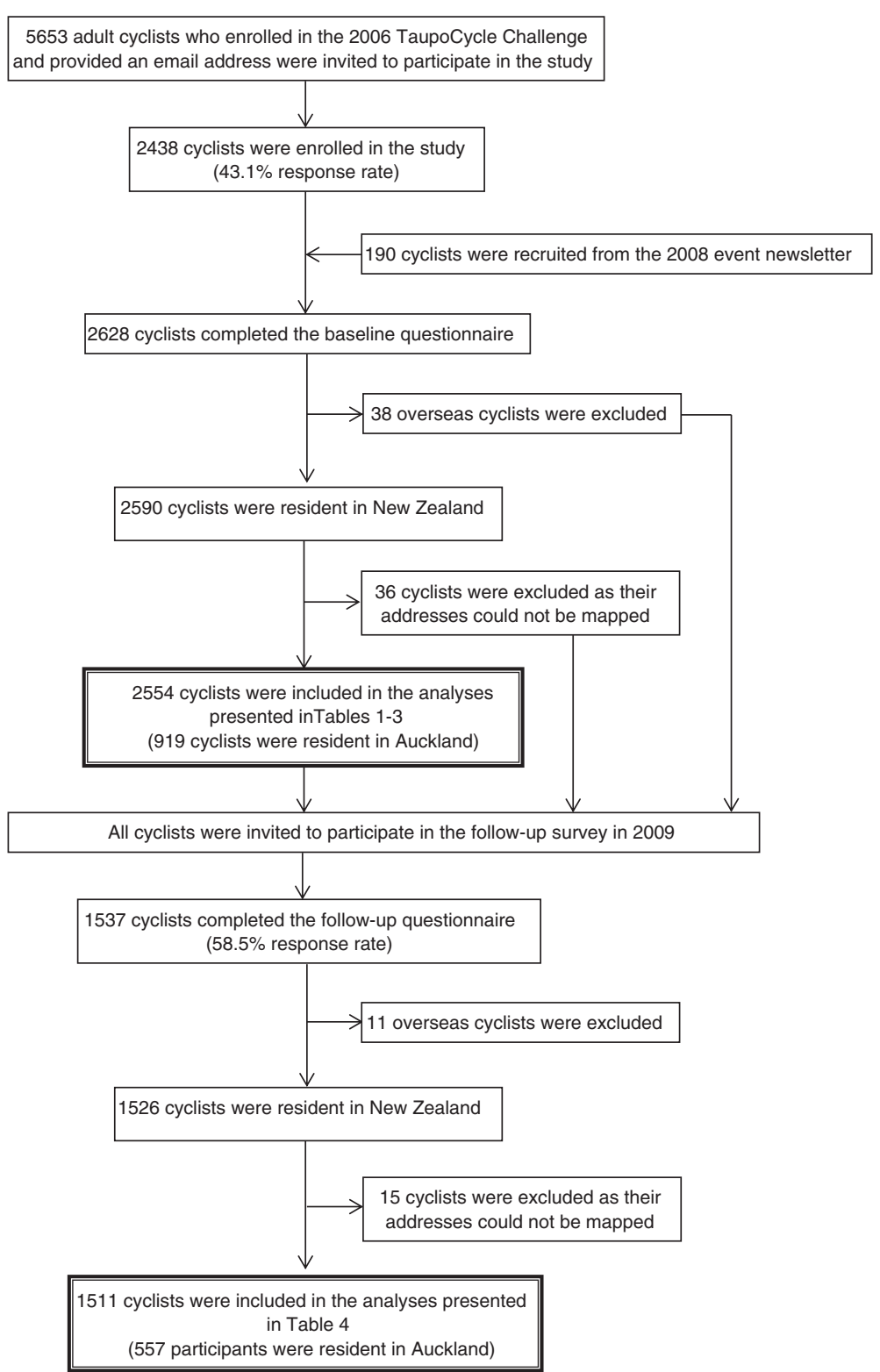

Figure 2 Flowchart of recruitment and follow-up of participants.

The hospital discharge data contains information about inpatients and day patients discharged after a minimum stay of three hours from all public hospitals and over $90 \%$ of private hospitals in New Zealand [24]. The mortality data contains information about all deaths registered in the country [25]. Diagnoses in each hospital visit and underlying causes of death are coded under ICD-10-AM. Bicycle crashes were identified using the E codes V10-V19 and those that occurred on public roads were identified using the $\mathrm{E}$ codes V10-V18.3-9, V19.4-6, and V19.9. Readmissions were identified as described previously [26] and excluded.
In New Zealand, it is mandatory that any fatal or injury crash involving a collision with a motor vehicle on a public road be reported to the police. The crash analysis system data contains information on all police-reported bicycle collisions involving a motor vehicle.

For each participant, bicycle crashes identified across different databases were matched based on the date of crash allowing for a two-day difference, so as to avoid double-counting of the same crash.

\section{Analyses}

The study sample was restricted to 2590 participants who were resident in New Zealand at recruitment. Participants' 
addresses were aggregated into meshblocks, the smallest geographic units used by Statistics New Zealand. The meshblocks were then categorised as Auckland and other regions, and also as main urban areas (centres with populations of 30000 or more) and others [27]. To assess the degree of neighbourhood deprivation, the meshblocks were also mapped on to the 2006 New Zealand Deprivation Index (NZDep) [28] with decile ten the most deprived and decile one the least. This analysis excluded 36 participants whose addresses could not be mapped.

All analyses were performed using SAS (release 9.2, SAS Institute Inc., Cary, North Carolina). Baseline data were presented as means with standard deviations and medians with interquartile ranges for continuous variables and percentages for categorical variables. All the data were complete for 2435 participants (95.3\%). Missing values were computed using multiple imputation with 25 complete datasets created by the Markov chain Monte Carlo method [29], incorporating all baseline covariates and injury outcomes. Crude and adjusted differences in baseline characteristics between the Auckland participants and the rest of the cohort were assessed using PROC GLM. In general, differences in residential characteristics were adjusted for demographic factors; differences in cycling characteristics were adjusted for demographic and residential factors; and differences in risk behaviours were adjusted for demographic, residential and cycling factors.

Bicycle crashes extracted through record linkage were categorised into on-road crashes (crashes that occurred on public roads) and others. As more than a single crash may be experienced during follow-up, incidence rates of repeated events were calculated separately for the Auckland participants and the rest of the cohort using the personyears approach. Confidence intervals were based on the Poisson distribution. The participants were censored on 30 June 2011 or date of death.

Cox proportional hazards regression modelling for repeated events were performed using a counting process approach to assess hazards of bicycle crash injury associated with residing in Auckland. Hazard ratios (HR) were sequentially adjusted for four domains of covariates: demographic, residential, cycling and behavioural risk factors (Figure 1). The mediating role of each domain was determined by the percentage reduction in the $\beta$ coefficient after inclusion of each domain in the model using the approach described previously [30]: $100 \times\left(\beta_{\text {crude }}-\beta_{\text {adjusted }}\right) / \beta_{\text {crude. }}$. The $95 \%$ confidence intervals relating to each percentage attenuation were estimated using a nonparametric bootstrapping method with 2000 re-samplings (with replacement).

Finally, the data from the resurvey involving 1511 participants were used to compare perceptions of environmental factors that would influence cycling for transportation between the Auckland participants and others. For this analysis, the response options were dichotomised into 'important' (i.e., important and very important) and 'not important'. Differences in perception were assessed using PROC GLM and adjusted for demographic, residential and cycling factors.

\section{Results}

Of the 2554 participants who provided a complete New Zealand address at recruitment, 919 (36.0\%) resided in the Auckland region. The Auckland participants did not differ from others by age and gender but were less likely to be Mãori and more likely to be university graduates and reside in urban areas and least deprived neighbourhoods (Table 1). They had fewer years of cycling experience but cycled as much as others. They spent less time cycling off-road and more time cycling in the dark or in a bunch; and were less likely to commute by a bicycle. They were more likely to ride a road bike and use lights while riding in the dark but less likely to use reflective materials.

During a median follow-up of 4.6 years, 322 Auckland participants experienced 538 bicycle crashes, of which 337 occurred on public roads including one death due to a collision with a motor vehicle (Table 2). This corresponds to 133 crashes (95\% CI: 121.93, 144.64), including 83 on-road crashes (95\% CI: 74.55, 92.57), per 1000 person-years. The Auckland participants had a higher risk of on-road crashes (Crude HR 1.47; 95\% CI: 1.22, 1.76) but had a similar risk of off-road crashes (Crude HR 0.96; 95\% CI: 0.77, 1.21) compared to others.

The higher risk of on-road bicycle crashes in the Auckland participants was partly mediated by differences in baseline characteristics (Table 3). Demographic factors modestly attenuated the crude HR by $4 \%(95 \%$ CI: $-1,14)$. Subsequent adjustment for residential, cycling and behavioural risk factors resulted in a further $20 \%, 27 \%$ and $2 \%$ reduction in the HR. In particular, urban residence, time spent cycling off-road, time spent cycling in the dark and time spent cycling in a bunch contributed most. Overall, factors included in the fully adjusted model accounted for a $53 \%(95 \%$ CI: 20,72$)$ of the regional differential in crash risk.

In addition, there were regional differences in participants' perceptions of environmental factors likely to influence cycling for transportation (Table 4). The Auckland participants were more likely to report 'driver attitude and behaviour,' 'road safety', 'traffic en route, 'need a car for other reasons (e.g., school run), 'breathing polluted air' and 'personal security' as important factors that would prevent cycling for transportation. They were also more likely to report 'more bike lanes', 'changing driver attitude and behaviour,' 'reduced vehicle speed' and 'bike friendly public transport' but were less likely to report 'rising costs of fuel' as important factors that would encourage cycling for transportation. Moreover, they were more likely to report 
Table 1 Baseline characteristics of the participants in Auckland vs. the rest of New Zealand

\begin{tabular}{|c|c|c|c|c|c|}
\hline \multirow[t]{2}{*}{ Baseline characteristics } & & \multirow{2}{*}{$\begin{array}{l}\text { Auckland } \\
(\mathrm{N}=919)\end{array}$} & \multirow{2}{*}{$\begin{array}{c}\text { Others } \\
(\mathrm{N}=1635)\end{array}$} & \multicolumn{2}{|c|}{ P-value } \\
\hline & & & & Crude & Adjusted \\
\hline Age & Mean (SD) & $43.8(10.6)$ & $44.1(10.3)$ & 0.5 & \\
\hline Male & $\%$ & 73.5 & 71.8 & 0.4 & \\
\hline Māori & $\%$ & 2.5 & 5.0 & 0.003 & \\
\hline \multicolumn{6}{|l|}{ Education } \\
\hline High school (secondary) or less & $\%$ & 17.6 & 22.1 & 0.007 & $0.01^{\mathrm{a}}$ \\
\hline Polytechnic & $\%$ & 20.2 & 28.0 & $<0.0001$ & $<0.0001^{\mathrm{a}}$ \\
\hline University & $\%$ & 61.9 & 49.6 & $<0.0001$ & $<0.0001^{\mathrm{a}}$ \\
\hline Missing & $\%$ & 0.2 & 0.2 & & \\
\hline Body mass index & Mean (SD) & $25.2(3.3)$ & $25.4(3.8)$ & 0.1 & $0.3^{\mathrm{a}}$ \\
\hline Missing & $\%$ & 0.7 & 0.6 & & \\
\hline \multicolumn{6}{|l|}{ NZDep 2006 score } \\
\hline $1-3$ & $\%$ & 57.1 & 46.9 & $<0.0001$ & $<0.0001^{b}$ \\
\hline $4-7$ & $\%$ & 32.9 & 37.7 & 0.01 & $0.03^{b}$ \\
\hline $8-10$ & $\%$ & 10.0 & 15.4 & 0.0001 & $0.0002^{b}$ \\
\hline Main urban area & $\%$ & 95.5 & 69.4 & $<0.0001$ & $<0.0001^{b}$ \\
\hline \multirow[t]{2}{*}{ Years of cycling } & Mean (SD) & $6.4(8.3)$ & $7.2(9.2)$ & 0.02 & $0.006^{c}$ \\
\hline & Median (IQR) & $3.0(7.0)$ & $3.0(8.5)$ & & \\
\hline Missing & $\%$ & 0.7 & 0.3 & & \\
\hline \multirow[t]{2}{*}{ Time spent cycling (hours per week) } & Mean (SD) & $5.8(3.6)$ & $5.7(3.8)$ & 0.3 & $0.4^{c}$ \\
\hline & Median (IQR) & $5.0(4.5)$ & $5.0(5.0)$ & & \\
\hline Missing & $\%$ & 0.2 & 0.4 & & \\
\hline \multirow[t]{2}{*}{$\%$ cycling off-road } & Mean (SD) & $5.8(14.8)$ & $9.8(19.6)$ & $<0.0001$ & $<0.0001^{c}$ \\
\hline & Median (IQR) & $0.0(5.0)$ & $0.0(10.0)$ & & \\
\hline Missing & $\%$ & 0.4 & 0.6 & & \\
\hline \multirow[t]{2}{*}{$\%$ cycling in the dark } & Mean (SD) & $11.7(16.4)$ & $7.5(12.0)$ & $<0.0001$ & $<0.0001^{c}$ \\
\hline & Median (IQR) & $5.0(20.0)$ & $1.0(10.0)$ & & \\
\hline Missing & $\%$ & 0.2 & 0.2 & & \\
\hline \multirow[t]{2}{*}{$\%$ cycling in a bunch } & Mean (SD) & $23.7(28.1)$ & $17.2(23.2)$ & $<0.0001$ & $<0.0001^{c}$ \\
\hline & Median (IQR) & $10.0(45.0)$ & $5.0(25.0)$ & & \\
\hline Missing & $\%$ & 0.8 & 0.8 & & \\
\hline Cycle to work at least once a week & $\%$ & 26.7 & 31.3 & 0.05 & $<0.0001^{c}$ \\
\hline Missing & $\%$ & 1.9 & 1.9 & & \\
\hline Mainly use road bike & $\%$ & 89.5 & 85.0 & 0.001 & $0.0007^{c}$ \\
\hline Missing & $\%$ & 0.4 & 0.5 & & \\
\hline Crash in the past 12 months & $\%$ & 32.5 & 29.9 & 0.2 & $0.9^{c}$ \\
\hline Missing & $\%$ & 0.2 & 0.2 & & \\
\hline Always wear helmet & $\%$ & 98.6 & 98.7 & 1 & $0.5^{d}$ \\
\hline Missing & $\%$ & 0.4 & 0.4 & & \\
\hline \multicolumn{6}{|l|}{ Wear fluorescent colours } \\
\hline Always & $\%$ & 29.8 & 28.8 & 0.6 & $0.2^{d}$ \\
\hline Sometimes & $\%$ & 49.5 & 51.3 & 0.4 & $0.4^{d}$ \\
\hline Never & $\%$ & 19.7 & 19.1 & 0.7 & $0.7^{d}$ \\
\hline
\end{tabular}


Table 1 Baseline characteristics of the participants in Auckland vs. the rest of New Zealand (Continued)

\begin{tabular}{|c|c|c|c|c|c|}
\hline Missing & $\%$ & 1.0 & 0.7 & & \\
\hline Always use lights in the dark ${ }^{\mathrm{e}}$ & $\%$ & 85.4 & 80.8 & 0.02 & $0.6^{\mathrm{d}}$ \\
\hline Missing & $\%$ & 0.1 & 0.0 & & \\
\hline \multicolumn{6}{|l|}{ Use reflective materials in the dark ${ }^{\mathrm{e}}$} \\
\hline Always & $\%$ & 44.9 & 51.7 & 0.006 & $0.02^{d}$ \\
\hline Sometimes & $\%$ & 27.4 & 29.0 & 0.5 & $0.1^{\mathrm{d}}$ \\
\hline Never & $\%$ & 27.3 & 19.0 & $<0.0001$ & $<0.0001^{d}$ \\
\hline Missing & $\%$ & 0.5 & 0.3 & & \\
\hline Ever listen to music while riding & $\%$ & 16.3 & 16.3 & 0.9 & $0.3^{d}$ \\
\hline Missing & $\%$ & 0.8 & 0.4 & & \\
\hline
\end{tabular}

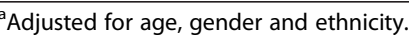

${ }^{\mathrm{b}}$ Adjusted as above plus education and BMI.

${ }^{c}$ Adjusted as above plus NZDep 2006 scores and urban residence.

${ }^{\mathrm{d}}$ Adjusted as above plus years of cycling, time spent cycling,\% cycling off-road,\% cycling in the dark, \% cycling in a bunch, cycle to work, mainly use road bike and baseline crash history.

${ }^{\text {e }}$ Restricted to 1708 participants who reported cycling in the dark.

'showers' and 'charges for car parking' as important factors that would encourage cycle commuting.

\section{Discussion}

\section{Main findings}

In this study, the risk of on-road bicycle crashes was $47 \%$ higher for participants who were resident in the Auckland region at recruitment compared to others. Approximately $53 \%$ of the excess risk was attributed to differences specifically examined in the study, particularly cycling off-road, in the dark and in a bunch and urban residence. Differences in Auckland and non-Auckland participants' perception of environmental determinants of cycling relating to other dangers of the traffic environment suggest other factors that could explain the remaining difference in crash risk.

\section{Strengths and limitations}

In this prospective cohort study, baseline data were near-complete as mandatory fields and validation checks were incorporated in the web questionnaire. Crash outcome data were collected from four administrative databases, thereby minimising potential biases associated with loss to follow-up and self-reports.

This analysis, however, excludes minor crashes not coming to the attention of the police or medical personnel, which amounts to more than two-thirds of self-reported crashes in this study [31]. Ascertainment of

Table 2 Bicycle crashes experienced during follow-up in Auckland vs. the rest of New Zealand

\begin{tabular}{|c|c|c|c|c|c|c|c|c|c|c|c|c|}
\hline \multirow{3}{*}{$\begin{array}{l}\text { Number of crashes experienced } \\
\text { by each participant }\end{array}$} & \multicolumn{4}{|c|}{ All crashes } & \multicolumn{4}{|c|}{ On-road crashes } & \multicolumn{4}{|c|}{ Off-road crashes } \\
\hline & \multicolumn{2}{|c|}{ Auckland } & \multicolumn{2}{|c|}{ Others } & \multicolumn{2}{|c|}{ Auckland } & \multicolumn{2}{|c|}{ Others } & \multicolumn{2}{|c|}{ Auckland } & \multicolumn{2}{|c|}{ Others } \\
\hline & $\mathrm{N}$ & $\%$ & $\mathrm{~N}$ & $\%$ & $\mathrm{~N}$ & $\%$ & $\mathrm{~N}$ & $\%$ & $\mathrm{~N}$ & $\%$ & $\mathrm{~N}$ & $\%$ \\
\hline 1 & 211 & 22.96 & 362 & 22.14 & 157 & 17.08 & 261 & 15.96 & 117 & 12.73 & 207 & 12.66 \\
\hline 2 & 57 & 6.20 & 103 & 6.30 & 39 & 4.24 & 51 & 3.12 & 22 & 2.39 & 44 & 2.69 \\
\hline 3 & 31 & 3.37 & 35 & 2.14 & 20 & 2.18 & 6 & 0.37 & 3 & 0.33 & 16 & 0.98 \\
\hline 4 & 9 & 0.98 & 19 & 1.16 & 4 & 0.44 & 6 & 0.37 & 2 & 0.22 & 7 & 0.43 \\
\hline 5 & 8 & 0.87 & 6 & 0.37 & 1 & 0.11 & 2 & 0.12 & 3 & 0.33 & 1 & 0.06 \\
\hline 6 & 2 & 0.22 & 2 & 0.12 & 2 & 0.22 & & & 0 & 0.00 & & \\
\hline 7 & 1 & 0.11 & & & 0 & 0.00 & & & 0 & 0.00 & & \\
\hline 8 & 2 & 0.22 & & & 0 & 0.00 & & & 1 & 0.11 & & \\
\hline 9 & 1 & 0.11 & & & 1 & 0.11 & & & & & & \\
\hline Total number of crashes & \multicolumn{2}{|c|}{538} & \multicolumn{2}{|c|}{791} & \multicolumn{2}{|c|}{337} & \multicolumn{2}{|c|}{415} & \multicolumn{2}{|c|}{201} & \multicolumn{2}{|c|}{376} \\
\hline Rate per 1000 person years & \multicolumn{2}{|c|}{132.92} & \multicolumn{2}{|c|}{108.14} & \multicolumn{2}{|c|}{83.20} & \multicolumn{2}{|c|}{56.73} & \multicolumn{2}{|c|}{49.66} & \multicolumn{2}{|c|}{51.40} \\
\hline$(95 \% \mathrm{Cl})$ & $(121$ & 144.64) & \multicolumn{2}{|c|}{$(100.73,115.94)$} & \multicolumn{2}{|c|}{$(74.55,92.57)$} & \multicolumn{2}{|c|}{$(51.41,62.46)$} & \multicolumn{2}{|c|}{$(43.03,57.02)$} & \multicolumn{2}{|c|}{$(46.34,56.87)$} \\
\hline Crude hazard ratio $(95 \% \mathrm{Cl})$ & \multicolumn{4}{|c|}{$1.23(1.06,1.42)$} & \multicolumn{4}{|c|}{$1.47(1.22,1.76)$} & \multicolumn{4}{|c|}{$0.96(0.77,1.21)$} \\
\hline
\end{tabular}


Table 3 Risk of on-road bicycle crashes in Auckland vs. the rest of New Zealand with stepwise adjustments

\begin{tabular}{|c|c|c|c|c|}
\hline Models & Additional variables in the model & Beta estimates (SE) & Hazard ratios $(95 \% \mathrm{Cl})$ & $\%$ Attenuation $(95 \% \mathrm{Cl})^{\mathrm{a}}$ \\
\hline 1. Unadjusted & & $0.382(0.073)$ & $1.47(1.27,1.69)$ & \\
\hline \multirow[t]{5}{*}{ 2. Model $1+$ demographics } & Age & $0.377(0.073)$ & $1.46(1.26,1.68)$ & \\
\hline & Gender & $0.375(0.073)$ & $1.46(1.26,1.68)$ & \\
\hline & Ethnicity & $0.370(0.074)$ & $1.45(1.25,1.67)$ & \\
\hline & Education & $0.369(0.074)$ & $1.45(1.25,1.67)$ & \\
\hline & Body mass index & $0.365(0.074)$ & $1.44(1.25,1.67)$ & $4(-1,14)$ \\
\hline \multirow[t]{2}{*}{ 3. Model $2+$ residential factors } & NZDep 2006 scores & $0.368(0.074)$ & $1.44(1.25,1.67)$ & \\
\hline & Urban residence & $0.292(0.077)$ & $1.34(1.15,1.56)$ & $24(11,49)$ \\
\hline \multirow[t]{8}{*}{ 4. Model 3 + cycling characteristics } & Years of cycling & $0.291(0.077)$ & $1.34(1.15,1.56)$ & \\
\hline & Time spent cycling & $0.282(0.077)$ & $1.33(1.14,1.54)$ & \\
\hline & $\%$ cycling off-road & $0.245(0.078)$ & $1.28(1.10,1.49)$ & \\
\hline & $\%$ cycling in the dark & $0.217(0.079)$ & $1.24(1.06,1.45)$ & \\
\hline & $\%$ cycling in a bunch & $0.184(0.079)$ & $1.20(1.03,1.41)$ & \\
\hline & Cycle to work & $0.192(0.079)$ & $1.21(1.04,1.42)$ & \\
\hline & Mainly use road bike & $0.193(0.080)$ & $1.21(1.04,1.42)$ & \\
\hline & Crash history & $0.189(0.080)$ & $1.21(1.03,1.41)$ & $51(21,74)$ \\
\hline \multirow[t]{5}{*}{ 5. Model $4+$ risk behaviours } & Use helmet & $0.188(0.080)$ & $1.21(1.03,1.41)$ & \\
\hline & Use fluorescent colours & $0.188(0.079)$ & $1.21(1.03,1.41)$ & \\
\hline & Use lights in the dark & $0.189(0.079)$ & $1.21(1.03,1.41)$ & \\
\hline & Use reflective materials in the dark & $0.179(0.080)$ & $1.20(1.02,1.40)$ & \\
\hline & Listen to music while riding & $0.179(0.080)$ & $1.20(1.02,1.40)$ & $53(20,72)$ \\
\hline
\end{tabular}

${ }^{\mathrm{a}} 95 \%$ bootstrap confidence interval.

crash outcomes may be affected by personal, social and health service factors [32] as well as the quality of individual data sources [33-35] and record linkage [36]. Nevertheless, our risk estimates are likely to be conservative as potential misclassification of crash outcomes may be nondifferential in a prospective cohort study [37]. Self-reported exposure data may not be accurate and may change over time. In particular, migration may have occurred during follow-up. In the follow-up survey, however, only $1.1 \%$ of the Auckland participants reported moving to other regions and $1.3 \%$ reported moving overseas, and $0.3 \%$ of the participants from other regions moved to Auckland and 0.7\% reported moving overseas. In fact, misclassification of the mediating variables is more important than that of the exposure (due to migration) and may underestimate the\% attenuation presented in this paper [38]. Finally, our participants cannot be considered representative of all New Zealand cyclists; however, this may have minimal impact on the risk estimates [39]. Importantly, the participants represented a wide variation with regard to demographics, cycling exposure and experience.

\section{Interpretation}

There were significant differences in demographic, residential, cycling and some behavioural characteristics between the Auckland participants and the rest of the cohort. Similar demographic differences were observed in the general population (see Additional file 2). Moreover, compared to the national average, more people use a car and less use active transport modes in Auckland [16,40] despite its favourable climate [41]. The danger of the region's car dominated road environment is reflected in the participants' perceptions about the determinants of cycling. Consequently, the Auckland participants had a $47 \%$ higher risk of on-road bicycle crashes but had a similar risk of off-road crashes compared to others in the study.

Differences examined in this study accounted for $53 \%$ of the excess risk of on-road crashes in Auckland. The Auckland participants were less likely to be Māori and more likely to be socioeconomically advantaged, reflecting demographic differences observed in the general population (see Additional file 2). Demographic differences exist in the risk of bicycle-related injuries [8,21], but accounted for only $4 \%$ of the regional disparity in crash risk in this study. Urban residence, however, explained an additional $20 \%$ of the risk disparity. Of note, Auckland is New Zealand's largest urban region and its population density is more than double that of any other region. Previous studies show that the majority of on-road bicycle crashes occur in urban areas $[42,43]$ where there are more people, heavy traffic and 
Table 4 Environmental factors perceived as important in influencing cycling for transportation in Auckland vs. the rest of New Zealand

\begin{tabular}{|c|c|c|c|c|}
\hline \multirow[t]{2}{*}{ Environmental factors } & \multirow{2}{*}{$\begin{array}{c}\text { Auckland (\%) } \\
\mathrm{N}=557\end{array}$} & \multirow{2}{*}{$\begin{array}{c}\text { Others (\%) } \\
\mathrm{N}=954\end{array}$} & \multicolumn{2}{|c|}{ P-value } \\
\hline & & & Crude & Adjusted $^{a}$ \\
\hline \multicolumn{5}{|l|}{ Barriers to cycling for transportation } \\
\hline Adverse weather & 82.6 & 82.4 & 0.9 & 1 \\
\hline Too hilly & 20.1 & 24.5 & 0.05 & 0.1 \\
\hline Would take too long & 49.2 & 50.9 & 0.5 & 0.9 \\
\hline Too far & 41.3 & 42.5 & 0.7 & 0.7 \\
\hline Too short a distance to use a bike & 26.4 & 23.4 & 0.2 & 0.8 \\
\hline Personal security & 50.1 & 38.4 & $<0.0001$ & 0.0002 \\
\hline Road safety & 79.9 & 69.2 & $<0.0001$ & $<0.0001$ \\
\hline Traffic en route & 79.0 & 67.3 & $<0.0001$ & $<0.0001$ \\
\hline Driver attitude and behaviour & 80.8 & 71.5 & $<0.0001$ & $<0.0001$ \\
\hline Availability of other easier transport & 42.0 & 38.5 & 0.2 & 0.3 \\
\hline Need a car for other reasons (e.g., school run) & 72.9 & 67.6 & 0.03 & 0.01 \\
\hline Breathing polluted air & 50.1 & 41.3 & 0.0009 & 0.009 \\
\hline \multicolumn{5}{|l|}{ Enablers of cycling for transportation } \\
\hline More bike lanes & 91.4 & 87.4 & 0.02 & 0.04 \\
\hline More bike paths & 78.5 & 80.3 & 0.4 & 1 \\
\hline Need to negotiate fewer difficult intersections & 75.9 & 70.7 & 0.03 & 0.1 \\
\hline Better road conditions & 84.0 & 81.5 & 0.2 & 0.5 \\
\hline Reduced vehicle speed & 63.7 & 58.8 & 0.06 & 0.03 \\
\hline Changing driver attitude and behaviour & 90.1 & 84.7 & 0.003 & 0.01 \\
\hline Bike friendly public transport & 52.1 & 39.5 & $<0.0001$ & $<0.0001$ \\
\hline Secure bike parking in public places & 69.3 & 73.3 & 0.1 & 0.3 \\
\hline Bike designed for transportation & 26.6 & 29.0 & 0.3 & 0.07 \\
\hline Car parking restrictions & 32.1 & 32.2 & 1 & 0.7 \\
\hline Rising costs of petrol & 41.3 & 48.3 & 0.008 & 0.03 \\
\hline \multicolumn{5}{|l|}{ Enablers of cycling to work/education ${ }^{b}$} \\
\hline Showers & 94.1 & 88.8 & 0.002 & 0.03 \\
\hline Lockers and changing facilities & 90.6 & 84.7 & 0.004 & 0.1 \\
\hline Secure bike parking & 91.9 & 86.7 & 0.006 & 0.1 \\
\hline Pool bikes & 6.2 & 7.6 & 0.3 & 0.1 \\
\hline Financial assistance to buy a commuter bike & 10.3 & 9.7 & 0.7 & 0.4 \\
\hline Bike maintenance classes/facilities & 15.2 & 15.5 & 0.9 & 0.4 \\
\hline A more flexible dress code & 29.5 & 29.0 & 0.9 & 0.9 \\
\hline More flexible working hours & 38.5 & 40.2 & 0.6 & 0.6 \\
\hline Charges for car parking & 25.5 & 19.1 & 0.009 & 0.04 \\
\hline
\end{tabular}

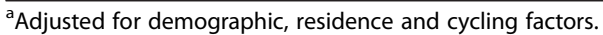

${ }^{\mathrm{b}}$ Restricted to participants who reported travelling to work/education at least once a week ( $\mathrm{N}=455$ in Auckland and $\mathrm{N}=734$ in the rest of New Zealand).

busy intersections while more severe crashes tend to be located in more remote areas where vehicles tend to travel at higher speeds [43-45]. However, it was not possible to differentiate crashes in terms of severity of injury in this study as multiple administrative databases were used.
Differences in cycling characteristics contributed to a further $27 \%$ attenuation in the hazard ratio. The greatest contribution came from less time spent cycling offroad and more time spent cycling in the dark and in a bunch by the Auckland participants. The former two 
may increase exposure to the crash risk but bunch riding has also been associated with a higher risk [21]. It is possible that cyclists are more likely to take risks [46] and less likely to notice road hazards [47] while riding in a group. Other cycling characteristics and behavioural factors such as use of visibility aids and distraction contributed modestly to regional differences in crash risk.

After all baseline differences were taken into account, the risk of on-road crashes was still 20\% higher among the Auckland cyclists. This may be explained by other contextual and environmental factors. While the climate may influence cycle volume [48] and safety [49], Auckland's relatively temperate climate is unlikely to be particularly hazardous. Similarly, with respect to topography, many parts of New Zealand are hillier than Auckland (see Additional file 1). Given the similarity in the risk of off-road crashes between Auckland and other regions, differences in travel patterns and traffic environment are more likely to contribute to the remaining disparity in crash risk.

Auckland is characterised by low density urban growth and an automobile-centred transportation system, encouraging car dependency, traffic congestion and air pollution $[50,51]$. This may pose risks to its users [52], particularly those who are vulnerable. Previous research on the 'safety in numbers' effect associated a higher risk of bicycle crashes with a lower level of cycling $[10,11]$. This is true in the New Zealand context particularly if the level of car use is also taken into account [14]. Moreover, a car-dominated road environment tends to discourage people from engaging in active travel [53]. In this study, the Auckland cyclists had more concerns about driver attitude and behaviour, traffic en route, difficult intersections, vehicle speed, road safety and polluted air, concerns which may be more prevalent in the general population [54].

\section{Conclusions}

The risk of on-road bicycle crashes was higher in Auckland than the rest of New Zealand. Approximately half of the excess risk was contributed by differences examined in this study particularly related to cycling patterns and urban residence. The remaining difference in crash risk may be explained by factors generally associated with the region's car-dominated transport environment. This underscores the need for cooperative efforts to promote cycling and cyclists' safety in the Auckland region.

\section{Additional files}

Additional file 1: Map of New Zealand. The boundary for the

Auckland region is marked in red.

Additional file 2: Characteristics of Auckland vs. New Zealand.

\section{Abbreviations}

ACC: Accident compensation corporation; Cl: Confidence interval; HR: Hazard ratio; ICD: International classification of diseases; NZDep: New Zealand deprivation index.

\section{Competing interests}

The authors declare that they have no competing interests.

\section{Authors' contributions}

STT contributed to the conception and design of the study, acquisition, analysis and interpretation of data and drafting of the manuscript. AW and SA contributed to the conception and design of the study, interpretation of data and revision of the manuscript. All authors read and approved the final manuscript.

\section{Acknowledgements}

We thank the participating cyclists and organisers of the Lake Taupo Cycle Challenge for their support, and Professor John Langley, Professor Anthony Rodgers and Dr Simon Thornley for their initial contribution to the study. Our thanks also go to the Accident Compensation Corporation, Ministry of Health and New Zealand Transport Agency for the provision of bicycle crash data; to Mr Roy Miodini Nilsen from the University of Bergen, Norway and Ms Silvia Stringhini from the Institute of Social and Preventive Medicine, Lausanne University Hospital, Switzerland for their kind assistance with bootstrap analyses; and to Ms Jinfeng Zhao from the University of Auckland for the provision of a map of New Zealand. This work was supported by the Health Research Council of New Zealand [grant number 09/142].

Received: 6 August 2013 Accepted: 4 December 2013

Published: 9 December 2013

\section{References}

1. Oja P, Titze S, Bauman A, de Geus B, Krenn P, Reger-Nash B, Kohlberger T: Health benefits of cycling: a systematic review. Scand J Med Sci Sports 2011, 21:496-509.

2. Litman T: Evaluating Transportation Equity: Guidance for Incorporating Distributional Impacts in Transportation Planning. Victoria Transport Policy Institute: Victoria; 2012

3. Higgins P: Exercise-based transportation reduces oil dependence, carbon emissions and obesity. Environ Conserv 2005, 32:197-202.

4. Mackie H: 'I Want to Ride my bike': Overcoming Barriers to Cycling to Intermediate Schools. Wellington: New Zealand Transport Agency Research Report No. 380; 2009

5. Winters M, Davidson G, Kao DN, Teschke K: Motivators and deterrents of bicycling: comparing influences on decisions to ride. Transportation 2011, 38:153-168

6. Bauman AE, Rissel C, Garrard J, Ker I, Speidel R, Fishman E: Cycling - Getting Australia Moving: Barriers, Facilitators and Interventions to get More Australians Physically Active Through Cycling. Cycling Promotion Fund: Melbourne; 2008.

7. van Bekkum JE, Williams JM, Morris PG: Cycle commuting and perceptions of barriers: stages of change, gender and occupation. Health Educ 2011, 111:476-497.

8. Tin Tin S, Woodward A, Ameratunga SN: Injuries to pedal cyclists on New Zealand roads, 1988-2007. BMC Public Health 2010, 10:655. doi:610.1186/ 1471-2458-1110-1655.

9. Wardlaw M: Assessing the actual risks faced by cyclists. Traffic Eng Control 2002, 43:420-424.

10. Jacobsen PL: Safety in numbers: more walkers and bicyclists, safer walking and bicycling. Inj Prev 2003, 9:205-209.

11. Robinson DL: Safety in numbers in Australia: more walkers and bicyclists, safer walking and bicycling. Health Promot J Austr 2005, 16:47-51.

12. Pucher J, Buehler R: Making cycling irresistable: lessons from the Netherlands, Denmark, and Germany. Transp Rev 2008, 28:495-528.

13. Vandenbulcke G, Thomas I, de Geus B, Degraeuwe B, Torfs R, Meeusen R, Int Panis L: Mapping bicycle use and the risk of accidents for commuters who cycle to work in Belgium. Transp Policy 2009, 16:77-87.

14. Tin Tin S, Woodward A, Thornley S, Ameratunga S: Regional variations in pedal cyclist injuries in New Zealand: safety in numbers or risk in scarcity? Aust N Z J Public Health 2011, 35:357-363.

15. de Geus B, Vandenbulcke G, Int Panis L, Thomas I, Degraeuwe B, Cumps E, Aertsens J, Torfs R, Meeusen R: A prospective cohort study on minor 
accidents involving commuter cyclists in Belgium. Accid Anal Prev 2012, 45:683-693.

16. Tin Tin S, Woodward A, Thornley S, Ameratunga S: Cycling and walking to work in New Zealand, 1991-2006: regional and individual differences, and pointers to effective interventions. Int I Behav Nutr Phys Act 2009, 6:64. doi:10.1186/1479-5868-1186-1164.

17. Ministry of Transport: Comparing Travel Modes. Wellington: Ministry of Transport; 2012

18. Ministry of Transport: How New Zealanders Travel: Trends in New Zealand Household Travel 1989-2008. Wellington: Ministry of Transport; 2009.

19. Statistics New Zealand: Subnational Population Estimates at 30 June 2012: Regional Council and Territorial Authority Areas. Wellington: Statistics New Zealand; 2012.

20. Agency NZT: Bicycle Crashes in the Auckland Region. New Zealand Transport Agency: Auckland; 2010.

21. Tin Tin S, Woodward A, Ameratunga S: Incidence, risk, and protective factors of bicycle crashes: findings from a prospective cohort study in New zealand. Prev Med 2013, 57:152-161.

22. Thornley SJ, Woodward A, Langley JD, Ameratunga SN, Rodgers A: Conspicuity and bicycle crashes: preliminary findings of the Taupo bicycle study. Inj Prev 2008, 14:11-18.

23. Accident Compensation Corporation: Annual Report 2012. Wellington: ACC; 2012.

24. Ministry of Health: National Minimum Dataset (Hospital Inpatient events): Data Mart-Data Dictionary V7.5. Wellington: Ministry of Health; 2012.

25. Ministry of Health: Mortality Collection Data Dictionary Version 1.3. Wellington: Ministry of Health; 2009.

26. Davie G, Samaranayaka A, Langley JD, Barson D: Estimating person-based injury incidence: accuracy of an algorithm to identify readmissions from hospital discharge data. Inj Prev 2011, 17:338-342.

27. Statistics New Zealand: New Zealand: An Urban/Rural Profile. Wellington: Statistics New Zealand; 2007.

28. Salmond C, Crampton P, Atkinson J: NZDep2006 Index of Deprivation. Wellington: Department of Public Health, University of Otago; 2007.

29. Schafer J: Analysis of Incomplete Multivariate Data. London: Chapman \& Hall; 1997.

30. Stringhini S, Sabia S, Shipley M, Brunner E, Nabi H, Kivimaki M, Singh-Manoux A: Association of socioeconomic position with health behaviors and mortality. JAMA 2010, 303:1159-1166.

31. Tin Tin S, Woodward A, Ameratunga S: Completeness and accuracy of crash outcome data in a cohort of cyclists: a validation study. BMC Public Health 2013, 13:420. doi:410.1186/1471-2458-1113-1420

32. Cryer C, Langley J: Developing Indicators of Injury Incidence That can be Used to Monitor Global, Regional and Local Trends. Dunedin: Injury Prevention Research Unit, University of Otago; 2008.

33. Davie G, Langley J, Samaranayaka A, Wetherspoon ME: Accuracy of injury coding under ICD-10-AM for New Zealand public hospital discharges. Inj Prev 2008, 14:319-323.

34. Health Outcomes International Pty Ltd: Methods and Systems Used to Measure and Monitor Occupational Disease and Injury in New Zealand NOHSAC Technical Report 2. Wellington: National Occupational Health and Safety Advisory Committee (NOHSAC); 2005.

35. McDonald G, Davie G, Langley J: Validity of police-reported information on injury severity for those hospitalized from motor vehicle traffic crashes. Traffic Inj Prev 2009, 10:184-190.

36. Clark DE: Practical introduction to record linkage for injury research Inj Prev 2004, 10:186-191.

37. Rothman K, Greenland S, Lash TL: Modern Epidemiology. 3rd edition. Philadelphia: Lippincott Williams \& Wilkins; 2008.

38. Blakely T, McKenzie S, Carter K: Misclassification of the mediator matters when estimating indirect effects. J Epidemiol Community Health 2013, 67:458-466.

39. Lash T, Fox M, Fink A: Applying Quantitative Bias Analysis to Epidemiological Data. New York: Springer; 2009.

40. Ministry of Transport: New Zealand Household Travel Survey: Regional Results 2003-2011 (3-Year Moving Average). Wellington: Ministry of Transport: 2012.

41. National Institute for Water \& Atmospheric Research (NIWA): Overview of New Zealand Climate. Wellington: NIWA; 2001.

42. Eilert-Petersson E, Schelp L: An epidemiological study of bicycle-related injuries. Accid Anal Prev 1997, 29:363-372.

43. Boufous $S$, de Rome $L$, Senserrick $T$, Ivers R: Risk factors for severe injury in cyclists involved in traffic crashes in Victoria, Australia. Accid Anal Prev 2012, 49:404-409.
44. Amoros $\mathrm{E}$, Chiron $\mathrm{M}$, Thelot $\mathrm{B}$, Laumon B: The injury epidemiology of cyclists based on a road trauma registry. BMC Public Health 2011, 11:653. doi:610.1186/1471-2458-1111-1653.

45. Kim J-K, Kim S, Ulfarsson GF, Porrello LA: Bicyclist injury severities in bicycle-motor vehicle accidents. Accid Anal Prev 2007, 39:238-251.

46. Johnson M, Oxley J, Cameron M: Cyclist Bunch Riding: A Review of the Literature. Victoria: Monash University Accident Research Centre; 2009.

47. Albert E: Dealing with danger: the normalization of risk in cycling. Int Rev Sociol Sport 1999, 34:157-171

48. Tin Tin S, Woodward A, Robinson E, Ameratunga S: Temporal, seasonal and weather effects on cycle volume: an ecological study. Environ Health 2012, 11:12. doi:10.1186/1476-1069X-1111-1112.

49. Gill M, Goldacre MJ: Seasonal variation in hospital admission for road traffic injuries in England: analysis of hospital statistics. Inj Prev 2009, 15:374-378.

50. Mees P, Dodson J: Backtracking Auckland: Bureaucratic Rationality and Public Preferences in Transport Planning. Urban Research Program Issue Paper 5. Brisbane: Griffith University; 2006.

51. Fisher G, Rolfe K, Kjellstrom T, Woodward A, Hales S, Sturman A, Kingham S, Petersen J, Shrestha R, King D: Health Effects due to Motor Vehicle Pollution in New Zealand. Ministry of Transport: Wellington; 2002.

52. Litman T: The Costs of Automobile Dependency and the Benefits of Balanced Transport. Victoria Transport Policy Institute: Victoria, BC; 2002.

53. Jacobsen PL, Racioppi F, Rutter H: Who owns the roads? How motorised traffic discourages walking and bicycling. Inj Prev 2009, 15:369-373.

54. Dill J: Categorizing cyclists: What do we know? Insights from Portland, OR. Presentation to Velo-City Global 2012. Vancouver, BC, Canada; 2012.

doi:10.1186/1476-069X-12-106

Cite this article as: Tin Tin et al:: The role of multilevel factors in geographic differences in bicycle crash risk: a prospective cohort study. Environmental Health 2013 12:106.

\section{Submit your next manuscript to BioMed Central and take full advantage of:}

- Convenient online submission

- Thorough peer review

- No space constraints or color figure charges

- Immediate publication on acceptance

- Inclusion in PubMed, CAS, Scopus and Google Scholar

- Research which is freely available for redistribution 